Journal de la Société des américanistes

Journal de la Société

des américanistes

tome $96, \mathrm{n}^{\circ} 1$

\title{
Declaración de guerra mapuche y valores sagrados
}

\section{Ximena Lois}

\section{OpenEdition}

\section{Journals}

Édition électronique

URL : https://journals.openedition.org/jsa/11401

DOI : 10.4000/jsa. 11401

ISSN : 1957-7842

\section{Éditeur}

Société des américanistes

\section{Édition imprimée}

Date de publication : 5 juin 2010

Pagination : 289-292

ISSN : 0037-9174

\section{Référence électronique}

Ximena Lois, « Declaración de guerra mapuche y valores sagrados », Journal de la Société des

américanistes [En ligne], 96-1 | 2010, mis en ligne le 25 octobre 2010, consulté le 04 septembre 2022. URL : http://journals.openedition.org/jsa/11401 ; DOI : https://doi.org/10.4000/jsa.11401 


\section{CHILI}

\section{DECLARACIÓN DE GUERRA MAPUCHE Y VALORES SAGRADOS}

El llamado hoy " conflicto mapuche » (hasta hace unos meses el gobierno y los medios de comunicación evitaban usar este concepto) tiene una larga historia en Chile. Durante los últimos diez años, sin embargo, se ha producido un escalamiento del conflicto y un recrudecimiento de la violencia con la cual se expresa. Los enfrentamientos de comuneros mapuches con carabineros de Chile (policía militarizada) en acciones relacionadas con la reivindicación de tierras (ocupación de predios, incendios), se vuelven cada vez más regulares y la reacción por parte de las fuerzas del orden del Estado cada vez más violenta; el resultado de esto es un número cada vez mayor de muertos, heridos y prisioneros mapuches, que reivindican para sí el estatus de presos políticos. La criminalización de la protesta mapuche alcanza extremos intolerables en el hecho que los juicios a estos prisioneros mapuches a menudo apelan a la ley antiterrorista que data de la época de la dictadura de Pinochet. Las penas por "incendios terroristas » son por supuesto mucho mayores que las por incendios comunes. Paralelamente, estudiantes universitarios de etnia mapuche y simpatizantes de su causa, desde casas de estudios de Temuco, Valdivia, Concepción y Santiago se enfrentan a carabineros en protestas habituales, por lo menos una vez al mes ${ }^{1}$.

Estas regulares movilizaciones han ido creciendo hasta alcanzar un nuevo estatus informativo. El día 20 de octubre de 2009, la Coordinadora AraucoMalleco (CAM), una de las dos mayores organizaciones mapuches en Chile, envió por e-mail el siguiente comunicado a la radio Bío-Bío:

Dado que no ha existido ninguna señal del gobierno de poner fin a las fuerzas represivas en nuestras comunidades hemos tomado una decisión [...]: manifestamos públicamente nuestra renuncia a la nacionalidad chilena, y declaramos territorio de la nación autónoma mapuche desde el río Bío-Bío al sur. Damos por terminado todo diálogo con la República de Chile y le declaramos la guerra desde hoy 20 de octubre de 2009 
en adelante. Y llamamos a todas esas comunidades a seguir la misma senda para poder lograr la expulsión completa a todos aquellos objetivos que operan en nuestra nación mapuche.

Este comunicado vino a subrayar el incendio de camiones madereros en la región de la Araucanía, acción reivindicada por esta misma organización.

Aunque no sabemos el eco que tendrá la declaración de la CAM en la población mapuche en general, y cualquiera que sea la reacción de las distintas partes del conflicto, este hecho debería llevarnos a una reflexión más profunda. ¿Por qué una comunidad minoritaria o, por lo menos, parte de ella, organizada y radicalizada, se siente en tal grado de frustración e impotencia como para llegar a declarar la guerra al Estado-nación en el cual vive desde hace dos siglos? La época de la transición a la democracia en Chile - a partir de 1990 -, fue un momento histórico que se vivió con mucha esperanza por parte de la comunidad mapuche, luego de la intensa represión y política indígena divisionista que ejercía el régimen de Pinochet. Si bien los distintos gobiernos de la concertación (centro-izquierda) que han seguido a la dictadura militar propusieron nuevas ideas para mejorar la relación del Estado con las comunidades indígenas (Ley Indígena aprobada en 1993, Comisión de Verdad Histórica y Nuevo Trato creada el año 2001), los últimos acontecimientos muestran una dolorosa evidencia: el Estado chileno ha fracasado hasta ahora en integrar a su minoría indígena más numerosa.

El estancamiento de un proceso de mejoría en las relaciones interculturales no puede deberse solamente o mayormente a la división interna de una de las partes, situación que a veces se le atribuye al pueblo mapuche. En el caso de conflictos culturales entre un Estado y una minoria indígena este argumento es incluso más débil, ya que el Estado posee los medios legales y la fuerza política para promover el desenlace del conflicto. Parece evidente a estas alturas que en Chile no ha habido realmente la voluntad y el coraje político para resolver los históricos atropellos que ha infligido el Estado a la comunidad mapuche en lo que a sus tierras ancestrales se refiere. Estudios científicos tienden a mostrar que para superar los conflictos entre grupos debe haber primeramente un reconocimiento del Otro. Por más exigencias y promesas que se hayan hecho por diferentes partes, la Constitución chilena todavía no hace referencia oficial al pueblo mapuche como constituyente de la nación; tal mención tiene una carga simbólica importante que podría hacer avanzar el proceso de reconciliación puesto que una revisión en este sentido le daría a la identidad mapuche un reconocimiento oficial. Otro aspecto que los estudios científicos han revelado es la importancia de los valores sagrados en las situaciones de conflicto ${ }^{2}$. En éstas, los valores sagrados se exacerban, brotan a la superficie de lo cotidiano y paralizan los mecanismos de solución. Los valores sagrados son aquellos que le dan cohesión al grupo, sin los cuales éste muere culturalmente. Todas las comisiones, acuerdos, tratados, 
ministerios, organizaciones e iniciativas diversas que el Estado chileno pueda proponer no surtirán efecto si no se toman en cuenta los valores sagrados de los mapuches al definir las políticas públicas.

La tierra para muchos grupos indígenas es algo relacional, un valor sagrado que no tiene intercambio posible con dinero u otros incentivos materiales. En esas tierras habitan sus muertos, en esos bosques actúan los espíritus guardianes de las relaciones ecológicas entre el hombre y la naturaleza; esto define al mismo tiempo aspectos fundamentales de los modelos mentales y dinámicas sociales del grupo. Los valores sagrados de las minorías no deben estar supeditados a los valores comerciales o monetarios de los Estados. La evolución misma de los pueblos y los acontecimientos en las relaciones entre ellos configuran nuevos valores sagrados. Así, valores que reivindican las nuevas generaciones de pueblos indígenas, tales como el autogobierno, la autonomía y la autodeterminación, se vuelven sagrados, prediciendo el rechazo a cualquier intercambio de éstos por incentivos materiales.

Un par de hechos en los últimos tiempos ilustran claramente la diferencia de posiciones de ambas partes frente al conflicto. En el mes de septiembre pasado (2009), el gobierno envió al Congreso un proyecto de ley que crea el ministerio de Asuntos Indígenas, así como una agencia de desarrollo indígena (reemplazando a la Corporación de desarrollo indígena, Conadi, desprestigiada por graves irregularidades internas), y un consejo de pueblos indígenas de 43 miembros. Esta iniciativa gubernamental fue rechazada por los mapuches, quienes consideran que no resuelve el problema de las tierras que reclaman. En el mismo mes de septiembre, el Consejo de todas las tierras, organización que agrupa a 160 comunidades y que, junto con la CAM, representa otra gran agrupación mapuche, propuso al gobierno un proyecto sobre participación política indígena en el cual se piden cupos reservados para indígenas en el Parlamento. La reserva de escaños para minorías, sobre todo representando a la zona de la Araucanía, significaría contar con un instancia para establecer un diálogo directo entre el gobierno y las comunidades, y sería un gesto simbólico que aumentaría la voz de los pueblos indígenas en los debates legislativos. Pero la solicitud no fue escuchada.

Si en una situación de conflicto cultural, como la de los mapuches con el Estado chileno, no existe primeramente un reconocimiento oficial de la existencia del Otro, y luego una inclusión y un respeto de los valores sagrados en las políticas públicas pertinentes, se corre el riesgo que, con el paso del tiempo y el agudizamiento del conflicto, sea más difícil el perdón oficial e histórico que también será necesario pronunciar.

\section{Ximena LoIs}

Institute for Social Research, Universtity of Michigan/ Chercheur associé à l'Institut Jean Nicod, Paris 


\section{NotAs}

1. Según el último censo oficial de 2002, Chile tiene una población de 15116435 , de los cuales 604349 se declaran pertenecientes al pueblo originario o indigena mapuche, es decir alrededor de un $4 \%$ del total de la población; este grupo representa el $87,3 \%$ de la población indigena de Chile. El censo de 1992, sin embargo, daba una cantidad de población mapuche de 932 000; esta disminución de un $30 \%$ en una década se ha interpretado como una manipulación estadística, o como consecuencia del cambio en la formulación de la pregunta (según algunas ONG la población mapuche sería actualmente entre 800000 y 1400 000). La Comisión ética contra la tortura, creada en 2001 por instituciones y personalidades que se destacaron en la defensa de los derechos humanos durante la dictadura militar, reportaba el 30 de septiembre pasado cerca de 100 indigenas encarcelados, condenados o procesados en Chile; en junio del presente año (2010) informaba de un total de 59 presos, condenados o procesados, revelando asi el recrudecimiento del conflicto en los últimos meses. Según esta Comisión el total de casos en que se ha aplicado la ley antiterrorista se eleva a 34 .

2. Sobre el tema de los valores sagrados en relación a otras poblaciones indigenas amerindias, véase Scott Atran y Douglas Medin, The native mind and the cultural construction of nature, The MIT Press, Cambridge Mass., 2008. Otro estudio sobre el mismo tema pero en el marco del conflicto israelopalestino, es él de Scott Atran, Robert Axelrod y Richard Davis, « Sacred barriers to conflict resolution », Science, 2007, 317, pp. 1039-1040. 